\section{Revista de la \\ Universidad del Thulia}

Fundada en 1947 por el Dr. Jesúns Enrique Lossada

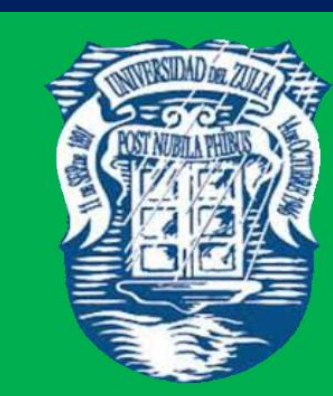

Ciencias del

Algreo

Ingemieria

y Teemología

\section{Aกัต 11 No 29}

Enero - Abril 2021

Tercera Época

Maracaibo-Venezuela 


\title{
Drug delivery via $\alpha$-Cyclodextrin: A Statistical-Nucleus Independent Chemical Shifts (S-NICS) study
}

\author{
Hediyeh Sadat Ghazimokri* \\ Majid Monajjemi** \\ Hossein Aghaie*
}

ABSRTACT

This study aims to investigate a novel method by using nucleus independent chemical shifts or S-NICS method of cyclo-dextrin. Monajjemi et.al (2008 a, 2015) has exhibited this novel method which so called "S-NICS" a few years ago. This program is arranged to calculate the aromaticities in some non-benzene rings. As the asymmetry ( $\eta$ ) and skew $(\kappa)$ parameters are fluctuated in a short and are alternative in lengthy distances, the S-NICS is a certain criterion for estimating the aromaticity. By generation of pseudo-random numbers in a Monte Carlo calculation which distributed in different function, the maximum abundant of skew and asymmetry parameters have been calculated for $\left(\eta^{*}\right),\left(\kappa^{*}\right)$, and lastly the modified isotropy $\left(\sigma_{\text {iso }}^{*}\right)$ has been calculated for $\alpha$-Cyclodextrin as an electromagnetic criterion. The results revealed that positive $S$ NICS and NICS values for $\alpha$-Cyclodextrin indicate anti-aromaticity. It was observed from the values of $\left(\eta^{*}\right),\left(\kappa^{*}\right)$ based on our calculations for $\alpha$-Cyclodextrin is negatives which are depending on the distances to the center of those rings. At last, by this work it has been presented a schematic diagram of S-NICS for post-ab-initio calculations.

KEYWORDS: Independent chemical shifts, S-NICS, Aromaticity, Monte Carlo, $\alpha$ Cyclodextrin.

"Department of Chemistry, Science and Research Branch, Islamic Azad University, Tehran, Iran.

${ }^{* *}$ Department of Chemical Engineering, Central Tehran Branch, Islamic Azad University, Tehran, Iran, majmonajjemi@iauctb.ac.ir

Recibido: 23/01/2020

Aceptado: 28/02/2020 


\section{Suministro de fármacos a través de la $\alpha$-ciclodextrina: un estudio de cambios químicos independientes del núcleo estadístico (S-NICS)}

Este estudio tiene como objetivo investigar un método novedoso mediante el uso de desplazamientos químicos independientes del núcleo, o el método S-NICS de ciclodextrina. Monajjemi et.al (2008 a, 2015) han exhibido este método novedoso que se llamó "S-NICS". Este programa está diseñado para calcular las aromaticidades en algunos anillos sin benceno. Como los parámetros de asimetría ( $\eta$ ) y sesgo ( ) fluctúan de forma breve y son alternativas en distancias largas, el S-NICS es un criterio determinado para estimar la aromaticidad. Mediante la generación de números pseudoaleatorios en un cálculo de Monte Carlo que se distribuyó en diferentes funciones, se calculó el máximo abundante de parámetros de asimetría y a simetría para $(\eta *),(\kappa *)$, y finalmente la isotropía modificada $\left(\sigma \_\right.$iso $\left.{ }^{\wedge}{ }^{*}\right)$ se ha calculado para la $\alpha-$ ciclodextrina como criterio electromagnético. Los resultados revelaron que los valores positivos de S-NICS y NICS para la $\alpha$-ciclodextrina indican anti-aromaticidad. Se observó que a partir de los valores de $(\eta *),(\kappa *)$ basados en nuestros cálculos para $\alpha$ ciclodextrina son negativos, que dependen de las distancias al centro de esos anillos. Finalmente, en este trabajo se ha presentado un diagrama esquemático de S-NICS para cálculos post-ab-initio.

PALABRAS CLAVE: Desplazamientos químicos independientes, S-NICS, Aromaticidad, Monte Carlo, $\alpha$-Ciclodextrina.

Introduction

The chemical shifts for molecular rings happen from the nucleolus of the magnetic fields with the steadiness of those external magnetic fields $\left(B_{0}\right)$. Generally, $B_{0}$ is a uniform field in the $z$-axis. The frequency, $v_{i}$, of an each nucleus inside of molecules are related to their gyromagnetic ratios, $v_{i}$, as specified by $v_{i}=\left(\gamma_{i} / 2 \pi\right) B_{0}\left(l-\sigma_{i}\right)$ (Mason, 1993).

The NICS (nucleus independent chemical shifts) method is a statistical computing approach that calculates the absolute magnetic shielding in the center of the ring. Negative S-NICS (Statistical-Nucleus Independent Chemical Shifts) values 
indicate aromaticity and in contrast the positive values are anti-aromaticity (Schleyer et al., 1996 and 1997).

For comparing the data together, another method which so-called "harmonic oscillator model" is used for estimating the aromaticity (HOMA) (Kruszewski and Krygowski, 1972), which are: (1) magnetic parameters of aromaticity (2) reactivity of aromatic compounds (3) geometrical considerations (4) the energetic approach to aromaticity (Stepien et al., 2004; Katritzky et al., 1989).

Through using of the energetic criterion for organizing of the aromatic molecules (Feixas et al., 2008), it is obvious that more stability of the structure might be appeared due to the cyclic electron delocalization (Fias et al., 2008; Hehre et al., 1970). Monajjemi and Boggs (2013) have demonstrated the low aromaticity for the borazine's ring of $\mathrm{B}_{18} \mathrm{~N}_{18}$ and $\mathrm{B}_{15} \mathrm{~N}_{15}$ (Monajjemi et al., 2010; Monajjemi and Khaleghian; 2011; Monajjemi 2012 and 2013).

Usually, aromatic ring has a downfield shift from the olefin area; hence, up-field shifts appear in the PNMR spectrums (Frueh,2002) which might be described as potential of a structure for sustaining a precipitated ring current. These molecules are known as dia-tropic and anti-aromatic and are called Para-tropic (Jiao and Schleyer, 1995).

In recent decades, aromaticity in terms of NICS in a long distances as the, NICS (0), at the center of ring through the aromatic ring current shielding (ARCS) method was estimated in several studies (Martin and Nance, 2002). In addition, S-NICS calculations, particularly in shortest ranges, have been investigated for relaxing of CSA (chemical shift anisotropies), dipole-dipole (Luginbhl and Wuthrich, 2002). It was shown that the asymmetry or $(\eta)$ and skew $(\kappa)$ parameters are fluctuated around the center of each ring.

This work is based on random movement of a probe in the shielding and deshielding space of aromatic and anti-aromatic molecules for understanding the anisotropic spin-spin interactions and spin-relaxation in short ranges (Beenakker et al., 1973). 
In other investigations, the components of Herzfeld and Haeberlen (Herzfeld and Berger, 1980), and CSA tensor has been calculated for $\mathrm{B}_{\mathrm{n}} \mathrm{N}_{\mathrm{n}} \mathrm{H}_{\mathrm{x}}$ rings $(\mathrm{n}=12,15,18)$ and $\mathrm{B}_{3} \mathrm{~N}_{3} \mathrm{H}_{\mathrm{n}}(\mathrm{n}=0,2,4,6,8$, (Monajjemi and Mohammadian, 2015). NICS values exhabite a little currents with no aromaticity for borazine because of the polar B-N bond while the S-NICS data indicate a strong stable aromaticity for borazine (Anet and O'Leary, 1992).

Cyclodextrins are natural nanoparticle that they are obtained by enzymatic digestion of starch. The $\alpha$ - $\beta$ - and $\gamma$ - cyclodextrins contain respectively 6,7 and 8 glucopyranose units, with primary and secondary hydroxyl groups located on the narrow and wider rims of a truncated cone shape structure (Boonyarattanakalin et al, 2012; Bhaskara et al., 2011). The steric arrangement of glucose units in the CD molecule brings in the shape of a hollow truncated cone with a hydrophilic external surface and a hydrophobic internal cavity, which permits CDs to form inclusion complexes with different guest molecules (Ibrahim et al., 2013).

The principal advantages of natural CDs as drug carriers are: (1) the availability of CDs of different cavity sizes, (2) a well-defined chemical structure, yielding many potential sites for chemical modification, (3) low toxicity and low pharmacological activity, (4) the protection of the included drug molecule from biodegradation (Fermeglia et al., 2003).

CDs are suitable compounds in supramolecular chemistries as receptors that are capable of including a range of organic, inorganic and biological compounds into their hydrophobic spaces in the non-covalent interactions (Del Valle, 2003; Ghatee and Sedghamiz, 2014). These non-toxic structures have interested not only in pharmaceutical industries, separation techniques, food industries, and molecule recognitions but also in environmental protections (Pan et al., 2011).

The objectives of these kind studies were to calculate the major components of Haeberlen's parameters and chemical shift anisotropies (CSA) for $\alpha$-Cyclodextrin. Scheme-1 shows the sphere region of S-NICS in the structure of $\alpha$-Cyclodextrin and it has been discussed those electronic properties in this structure for finding the reason 
of relative stabilities in this rings in view point of isotropies and anisotropies. Finally, the electronic structure of $\alpha$-Cyclodextrin has been studied by S-NICS method.

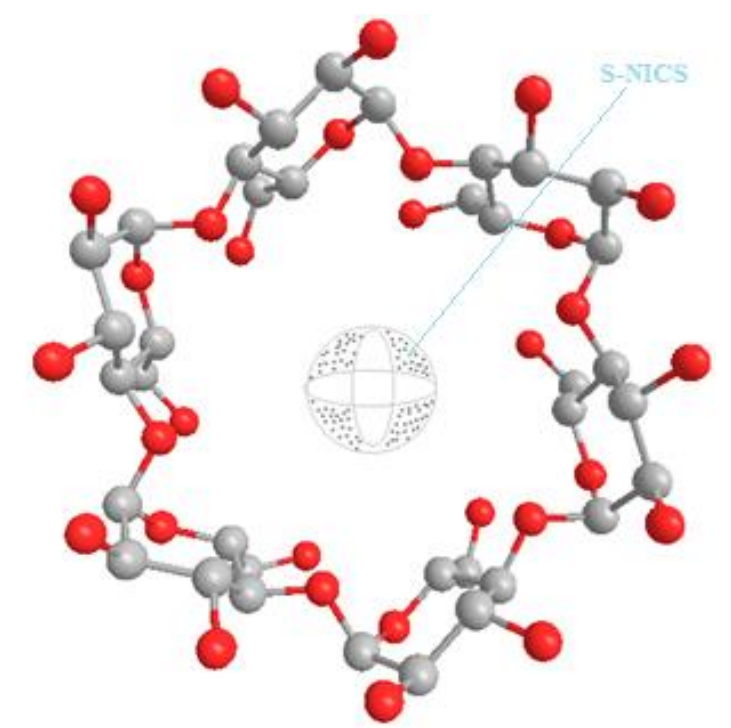

Scheme l. The sphere region of S-NICS in optimized structures of $\alpha$-Cyclodextrin.

1. Theory calculation

In using the CSA relaxation, anisotropy (CSA) means orientation dependence of the chemical shift and is described via a second-rank tensor, which includes six independent components (Mahdavian and Monajjemi, 2010).

It can be revised in its principal axis system, where it has a diagonal form. Where, the reduced anisotropy

$\Omega_{\mathrm{PAS}}^{(2)}=\frac{2}{3} \Delta \sigma\left[\begin{array}{ccc}-\frac{1}{2}(1+\eta) & 0 & 0 \\ 0 & -\frac{1}{2}(1-\eta) & 0 \\ 0 & 0 & 1\end{array}\right]=\zeta(z z)\left[\begin{array}{ccc}-\frac{1}{2}(1+\eta) & 0 & 0 \\ 0 & -\frac{1}{2}(1-\eta) & 0 \\ 0 & 0 & 1\end{array}\right]$

$\left[\zeta_{(z z)}=\left(\sigma_{z z}-\sigma_{\text {iso }}\right)=\left(\sigma_{33}-\sigma_{\text {iso }}\right)\right]$

and anisotropy $(\Delta \sigma)$ with relation of $\Delta \sigma=\frac{3}{2} \zeta_{(z z)}$ including shielding asymmetry $(\eta)$ can be defined as:

$$
\begin{aligned}
& \Delta \sigma=\sigma_{z z}-\frac{1}{2}\left(\sigma_{x x}-\sigma_{y y}\right) \\
& \eta=\left(\frac{\sigma_{y y}-\sigma_{x x}}{\zeta_{z z}}\right)==\frac{3\left(\sigma_{y y}-\sigma_{x x}\right)}{2 \Delta \sigma}
\end{aligned}
$$


The symmetric tensor in some cases, $\left(\sigma_{\mathrm{yy}}-\sigma_{\mathrm{xx}}\right)$ will be 0 and then $\eta=0$, (Ilkhani and Monajjemi, 2015) therefore, $(0 \leq \eta \leq+1)$ and $\Omega=\Omega^{(0)}+\Omega^{(1)}+\Omega^{(2)}$.

In spherical tensor investigated as Haeberlen and have estimated out, at fundamental stages in spherical styles.

$$
\sigma=\sigma^{\mathrm{iso}(0)}+\sigma^{\mathrm{ant}(1)}+\sigma^{\mathrm{sym}(2)}
$$

Spherical tensors are generally involved the effects of tensor quantities on density matrix (Samiei Soofiand and Monajjemi, 2016) as follows: (Monajjemi et al., 2008 a)

$$
\sigma_{0}^{\text {iso( }(2)}=\sqrt[2]{\frac{3}{2}} \zeta_{z z} \text { and } \sigma_{ \pm 2}^{\text {sym }(2)}=\frac{1}{2} \zeta_{z z}
$$

The proportionalities of those equations exhibit the shielding anisotropy and asymmetry which can readily be associated with a spherical tensor as follows:

$$
\sigma_{\text {iso }}=\sigma_{\text {avg }}\left[\begin{array}{lll}
1 & 0 & 0 \\
0 & 1 & 0 \\
0 & 0 & 1
\end{array}\right]
$$

The magnetic environment (Monajjemi and Chahkandi, 2005) of a spin is seldom isotropic. Hence, is described by a tensor of Span
$(\Omega)=\sigma_{33}-\sigma_{11}$
$(0 \leq \eta \leq+1)$

$\kappa=\frac{3\left(\sigma_{\text {iso }}-\sigma_{22}\right)}{\Omega} \quad(-1 \leq \kappa \leq+1)$

Based on the position of $\sigma_{22}$ with consideration of $\sigma_{\text {iso, }}$ the sign of $\kappa$ is either positive or negative (Monajjemi et al., 2008 b). Based on our calculations $\alpha$ Cyclodextrin, ( $\kappa)$ is negative.

Due to Herzfeld-Berger notation, (Herzfeld, 1980) three parameters have been defined with combination of the major components. Those are classified as; span $(\Omega)$, which describes the maximum width, $(\Omega \geq 0)$, skew $(\kappa)$ of the tensor.

\section{Result and Discussion}

Total shieldings such as standard components, Haeberlen- Mehring, and HerzfeldBerger parameters for $\alpha$-Cyclodextrin have been calculated via density functional theory. This study aims to investigate a statistical method by using computing of nucleus independent chemical shifts (S-NICS) in a sphere of shielding and de-shielding 
spaces of molecular rings. ONIOM method was applied to all calculation. CSA tensors and parameters for proton NMR in $\alpha$-Cyclodextrin Fig $1-2$ and Table 1 were calculated using the B3LYP method in conjunction with $6-31 G^{* *}, 6-31 G^{*}$ and $6-31 G$ basis sets.

In short distances from center, the asymmetric parameter $(\eta)$, and the skew $(\kappa)$, obey the Gaussian distribution on their fluctuation treatment, which is related to the distances of the molecular rings (Monajjemi et al., 2006, 2009, 2013, 2014). In the SNICS methods, the best point of the shielding placed around the center of symmetric or non-symmetric aromatic molecules which indicates an aromaticity criterion. In this method the expectation of the $\left(\eta^{*}\right)$ and $\left(\kappa^{*}\right)$ have been calculated as the Gaussian curve functions around the center of the $\alpha$-Cyclodextrin (Table 2$)$. The isotropy $\left(\sigma_{\text {iso }}^{*}\right)$ depending to $\left(\eta^{*}\right)$ and $\left(\kappa^{*}\right)$ and $\left(\Omega^{*}\right)$ and $\left(\zeta^{*}\right)$ are the best criterion for symmetric or nonsymmetric aromatic molecules (Table 2) (Monajjemi and Mohammadian, 2015).

It has been mentioned, a large point's random numbers in the space of shielding are needed to gain the most exact data of isotropy criterion. Similar to the NICS method, in S-NICS, negative nucleus-independent chemical shifts denote aromaticity and positive values denote anti-aromaticity (Monajjemi and Mohammadian, 2015). Consequently the chemical shielding, electronegativity, hydrogen bonding, and magnetic anisotropy of $\pi$-systems would be changed due to the electrons around the proton which produce a magnetic field, countering the applied field. Furthermore via the S-NICS, it can be estimated the most accurate places for effective points as an aromaticity criterion (Ardalan et al., 2014). The chemical shielding is a vector orientation function for all of the shielding parameters that can change in various places inside the shielding area of the rings for aromatic compounds and also for each cycles, the $(+)$ value denotes shielding and $(-)$ indicates de-shielding (Yahyaei and Monajjemi, 2014).

S-NICS have been investigated via the Monte Carlo model through computation of nucleus-independent chemical shifts around the ring of $\alpha$-Cyclodextrin. The asymmetry $(\eta)$, and skew $(\kappa)$ parameters fluctuate by the changing of tensors, while in the case of an axially symmetric tensor, $\sigma_{22}$ equals either $\sigma_{11}$ or $\sigma_{33}$ and $\mathrm{a}=\Omega / 3$, the span is $\kappa= \pm 1$ by changing asymmetry between $0 \leq \eta \leq+1$ and the span will be changed between 
$(-1 \leq \kappa \leq+1)$ and the parameter " $\kappa$ " is zero when $\sigma_{22}=\sigma_{\text {iso }}$ and the details of the statistical data such as expectation of these parameters and S-NICS data for $\alpha$-Cyclodextrin are shown Table 2.
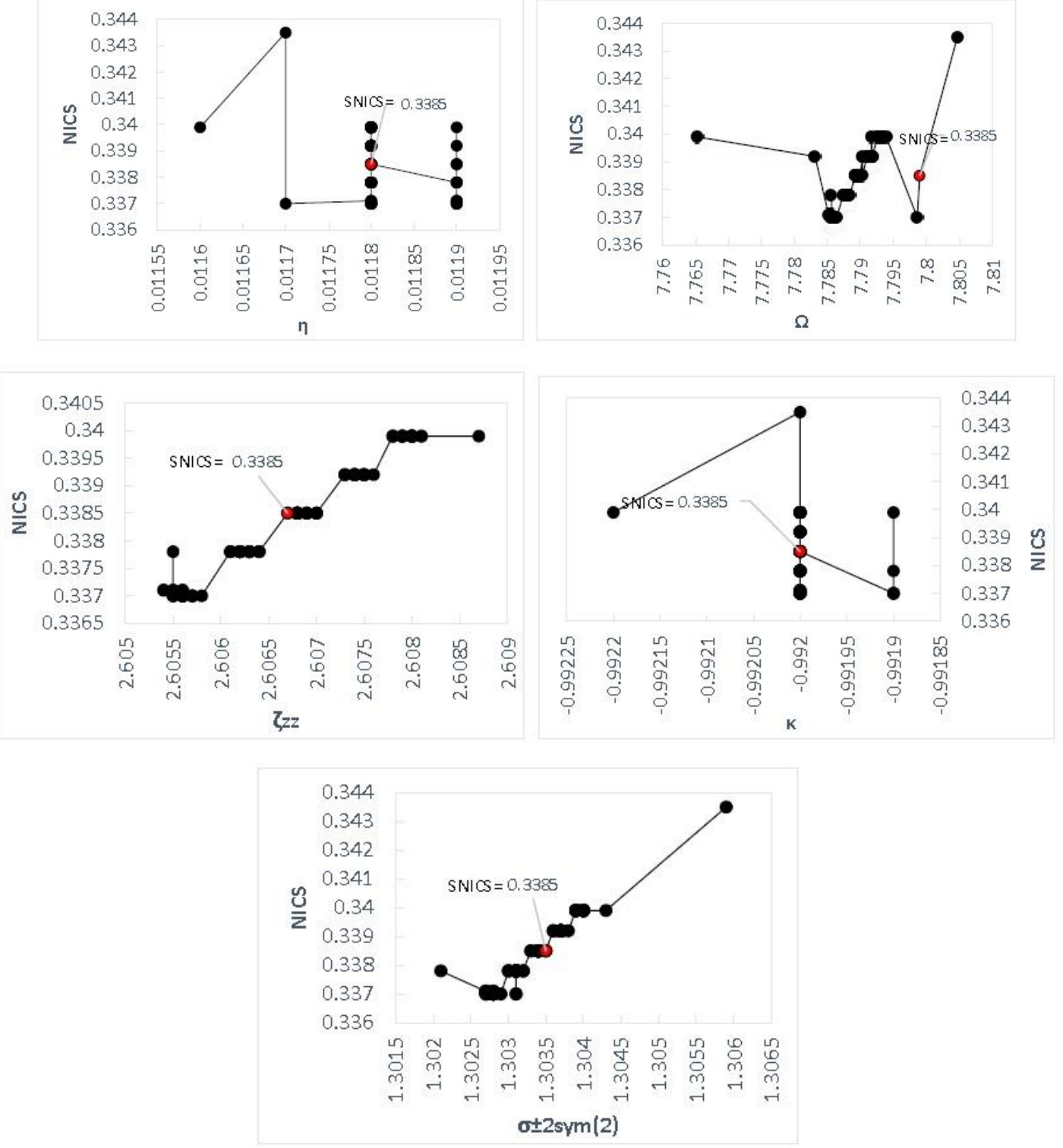

Fig 1. S-NICS (red point) from NICS calculation with $6-31 G^{* *}$ basis set.

As it can be seen in the schems2 and figures2, symmetry of density electron on $\alpha$-Cyclodextrin represents the regular rotation around the $z$ axis. $\alpha$-Cyclodextrin which accepts some molecular guests as hosts. Hamiltonian kinetics energy density $G(r)$ of $\alpha$ Cyclodextrin is shown in Scheme 3. The kinetics Hamiltonian represents a rotational direction and movement of the various segments of the $\alpha$-Cyclodextrin. 
REVISTA DE LA UNIVERSIDAD DEL ZULIA. $3^{a}$ época. Año 11 N² 29, 2020 Hediyeh Sadat Ghazimokri et al./// Drug delivery via $\alpha$-Cyclodextrin ...

Table 1. S-NICS parameters for $\alpha$-Cyclodextrin by $6-31 G^{*}$ basis set.

\begin{tabular}{|c|c|c|c|c|c|c|c|c|c|c|c|}
\hline $\mathrm{R}_{\mathrm{BQ}}$ & $\eta$ & $\bar{\Omega}$ & $\kappa$ & $\zeta_{z z}$ & $\boldsymbol{\sigma}_{ \pm 2}{ }^{\operatorname{sym}(2)}$ & $\mathrm{R}_{\mathrm{BQ}}$ & $\eta$ & $\bar{\Omega}$ & к & $\zeta_{z z}$ & $\begin{array}{c}\boldsymbol{\sigma}_{ \pm 2}{ }^{\operatorname{sym}(2} \\
)\end{array}$ \\
\hline 0.17320 & 0117 & 8017 & 0.9929 & 2.6118 & 1.3059 & 0.06708 & 0.0107 & 7.9603 & 0.9927 & 2.6629 & 1.3314 \\
\hline 0.12247 & 0.0105 & 7.9630 & -0.9927 & 2.6637 & 1.3318 & 0.05477 & 0.0107 & 7.9527 & -0.9927 & 2.6604 & 1.3302 \\
\hline 0.01732 & 0.0107 & 7.9520 & -0.9927 & 2.6602 & 1.3301 & 0.05744 & 0.0107 & 7.9548 & -0.9927 & 2.6611 & 1.3305 \\
\hline 0.02449 & 0.0107 & 7.9541 & -0.9927 & 2.6609 & 1.3304 & 0.06164 & 0.0107 & 7.9568 & -0.9928 & 2.6618 & 1.3309 \\
\hline 0.03316 & 0.0107 & 7.9561 & -0.9927 & 2.6616 & 1.3308 & 0.06708 & 0.0107 & 7.9587 & -0.9928 & 2.6625 & 1.3312 \\
\hline 0.04242 & 0.0118 & 7.7910 & -0.9920 & 2.6073 & 1.3036 & 0.07348 & 0.0107 & 7.9605 & -0.9928 & 2.6630 & 1.3315 \\
\hline 0.05196 & 0.0107 & 7.7598 & -1.0184 & 2.6628 & 1.3314 & 0.03316 & 0.0107 & 7.9522 & -0.9927 & 2.6603 & 1.3301 \\
\hline 0.02449 & 0.0107 & 7.9520 & -1.0183 & 2.6602 & 1.3301 & 0.03771 & 0.0108 & 7.9544 & -0.9927 & 2.6610 & 1.3305 \\
\hline 0.03 & 0.0107 & 7.9542 & -0.9927 & 2.6610 & 1.3305 & 0.04358 & 0.0107 & 7.9564 & -0.9927 & 2.6617 & 1.3308 \\
\hline 0.03741 & 0.0107 & 7.9563 & -0.9924 & 2.6616 & 1.3308 & 0.05099 & 0.0107 & 7.9583 & -0.9927 & 2.6623 & 1.3311 \\
\hline 0.04582 & 0.0107 & 7.9581 & -0.9927 & 2.6622 & 1.3311 & 0.05916 & 0.0107 & 7.9601 & -0.9927 & 2.6629 & 1.3314 \\
\hline 0.05477 & 0.0107 & 7.9599 & -0.9927 & 2.6628 & 1.3314 & 0.03741 & 0.0107 & 7.9523 & -0.9927 & 03 & 1.3301 \\
\hline 0.03316 & 0.0107 & 7.9522 & -0.9927 & 2.6602 & 1.3301 & 0.04123 & 0.0107 & 7.9544 & -0.9927 & 510 & 1.3305 \\
\hline 0.02 & & & & 2.6610 & & & & & & & 1.3308 \\
\hline 0.04358 & & 7.9563 & & 2.6616 & & 0.05385 & & 7.9583 & & 2.6623 & 1.3311 \\
\hline 0.0026 & 0.0107 & 7.9582 & -0.9927 & 2.6622 & 1.3311 & 0.07937 & 0.0107 & 7.9601 & -0.9927 & 2.6629 & 1.3314 \\
\hline 0.05916 & 0.0107 & 7.9600 & -0.9927 & 2.6628 & 1.3314 & 0.03741 & 0.0107 & 7.9525 & -0.9927 & 2.6604 & 1.3302 \\
\hline 0.04242 & 0.0107 & 7.9523 & -0.9928 & 2.6603 & 1.3301 & 0.04123 & 0.0107 & 7.9546 & -0.9927 & 2.6610 & 1.3305 \\
\hline 0.04582 & 0.0107 & 7.9545 & -0.9927 & 2.6610 & 1.3305 & 0.04690 & 0.0107 & 7.9566 & -0.9927 & 2.6617 & 1.3308 \\
\hline 0.05599 & 0.0107 & 7.9565 & -0.9928 & 2.6617 & 1.3308 & 0.05385 & 0.0107 & 7.9585 & -0.9927 & 2.6624 & 1.3312 \\
\hline 0.05744 & 0.0107 & 7.9584 & -0.9928 & 2.6623 & 1.3311 & 0.06164 & 0.0107 & 7.9602 & -0.9928 & 2.6630 & 1.3315 \\
\hline 0.06480 & 0.0107 & 7.9602 & -0.9928 & 2.6629 & 1.3314 & 0.05099 & 0.0107 & 7.9526 & -0.9928 & 2.6604 & 1.3302 \\
\hline 0.05196 & 0.0107 & 7.9526 & -0.9928 & 2.6604 & 1.3302 & 0.05385 & 0.0107 & 7.9547 & -0.9927 & 2.6611 & 1.3305 \\
\hline 0.05477 & 0.0107 & 7.9548 & -0.9927 & 2.6610 & 1.3305 & 0.05830 & 0.0107 & 7.9567 & -0.9928 & 2.6618 & 1.3309 \\
\hline 0.05916 & 0.0107 & 7.9567 & -0.9928 & 2.6617 & 1.3308 & & 0.0107 & 7.9586 & -0.9928 & 2.6624 & 1.3312 \\
\hline 0.06480 & 0.0107 & 7.9586 & -0.9928 & 2.6624 & 1.3312 & 0.0707 & 0.0107 & 7.9605 & -0.9928 & 2.6630 & 1.3315 \\
\hline 0.07141 & 0.0107 & 7.9604 & -0.9928 & 2.6630 & 1.3315 & 0.05916 & 0.0107 & 7.9529 & -0.9928 & 2.6604 & 1.3302 \\
\hline 0.02449 & 0.0108 & 7.9521 & -0.9927 & 2.6602 & 1.3301 & 0.06164 & 0.0107 & 7.9550 & -0.9928 & 2.6612 & 1.3306 \\
\hline 0.03605 & 0.0107 & 7.9542 & -0.9927 & 2.6610 & 1.3305 & 0.06557 & 0.0107 & 7.9570 & -0.9928 & 2.6618 & 1.3309 \\
\hline 0.03753 & 0.0107 & 7.9563 & -0.9927 & 2.6616 & 1.3308 & 0.07071 & 0.0107 & 7.9589 & -0.9928 & 2.6624 & 1.3312 \\
\hline 0.04582 & 0.0107 & 7.9582 & -0.9927 & 2.6622 & 1.3311 & 0.07681 & 0.0107 & 7.9606 & -0.9928 & 2.6630 & 1.3315 \\
\hline 0.05477 & 0.0107 & 7.9599 & -0.9927 & 2.6628 & 1.3314 & 0.04242 & 0.0108 & 7.9525 & -0.9927 & 2.6604 & 1.3302 \\
\hline 0.03 & 0.0107 & & & 2.6603 & 1.3301 & & 0.0108 & 7.9546 & -0.9927 & 2.6611 & 1.3305 \\
\hline 0.03464 & 0.0107 & 7.9543 & -0.9927 & 2.6610 & 1.3305 & 0.05099 & 0.0108 & 7.9566 & -0.9927 & 2.6618 & 1.3309 \\
\hline
\end{tabular}


REVISTA DE LA UNIVERSIDAD DEL ZULIA. $3^{a}$ época. Año 11 Nº 29, 2020

Hediyeh Sadat Ghazimokri et al./// Drug delivery via $\alpha$-Cyclodextrin ...
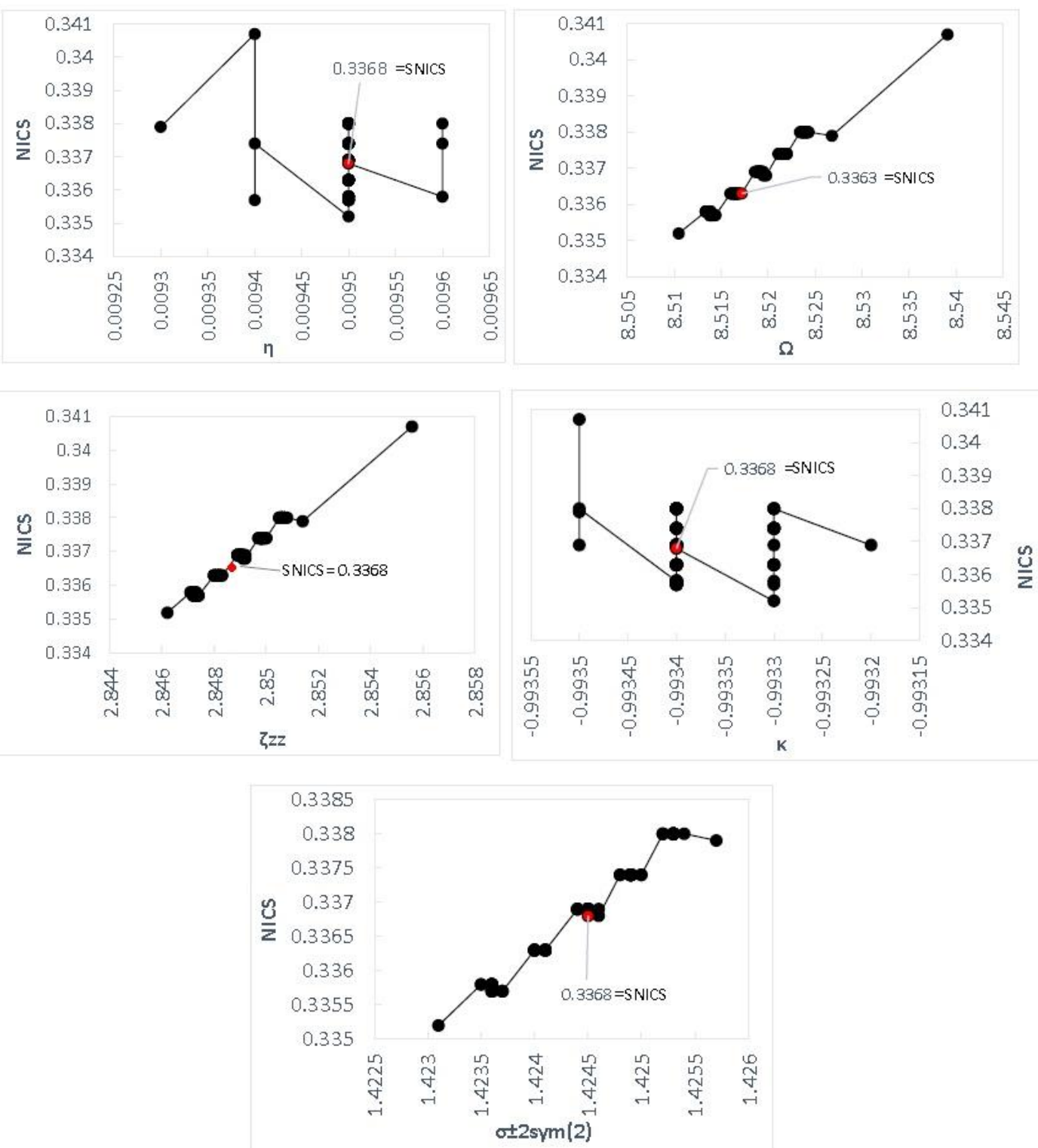

Fig 2. S-NICS (red point) from NICS calculation with 6-31G basis set.

Table 2. NICS and S-NICS parameters for $\alpha$-Cyclodextrin in different basis sets

\begin{tabular}{|c|c|c|c|c|c|c|c|c|c|}
\hline \multicolumn{10}{|c|}{$\boldsymbol{\alpha}$-Cyclodextrin } \\
\hline Basis set & $\zeta^{*}$ & $\boldsymbol{\eta}^{*}$ & $\Omega^{*}$ & $\mathbf{K}^{*}$ & S-NICS & NICS & $\mathrm{R}_{\mathrm{Bq}}$ & $\begin{array}{c}\text { (aniso) } \\
*\end{array}$ & $\begin{array}{c}\text { (NICS) } \\
*\end{array}$ \\
\hline $6-31 G^{* *}$ & 2.6068 & 0.0118 & 7.7294 & -0.992 & +0.338 & +0.336 & 0.0531 & 3.9103 & +0.338 \\
\hline $6-31 G^{*}$ & 2.8490 & 0.0094 & 8.5198 & -0.9937 & +0.336 & +0.335 & 0.0531 & 4.2736 & +0.337 \\
\hline $6-31 G$ & 2.6603 & 0.0107 & 7.9516 & -0.9932 & +0.3236 & +0.3213 & 0.0531 & 3.9909 & +0.3253 \\
\hline
\end{tabular}


REVISTA DE LA UNIVERSIDAD DEL ZULIA. $3^{a}$ época. Año $11 N^{\circ}$ 29, 2020

Hediyeh Sadat Ghazimokri et al./// Drug delivery via $\alpha$-Cyclodextrin ...

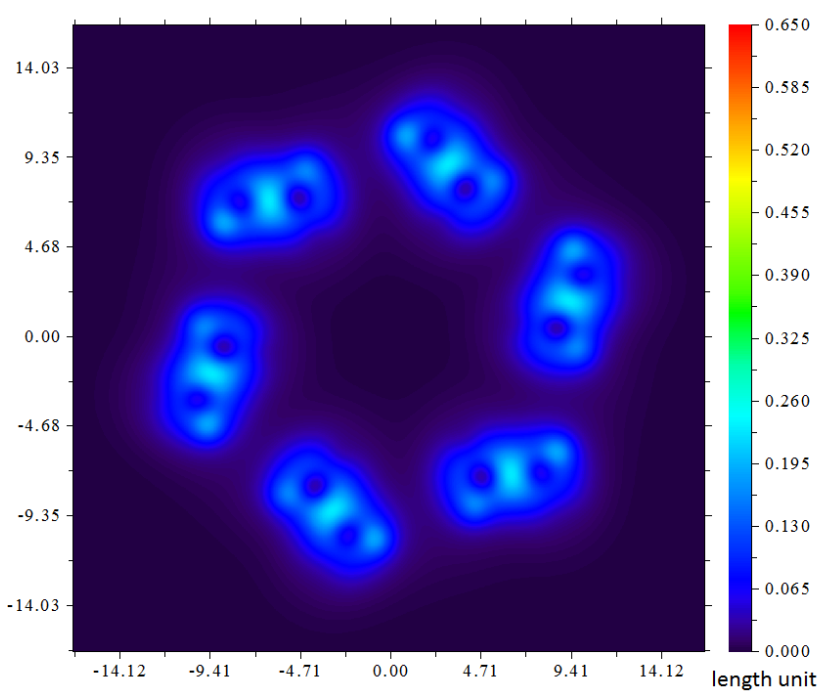

Scheme 2. Electron density of $\alpha$-Cyclodextrin.

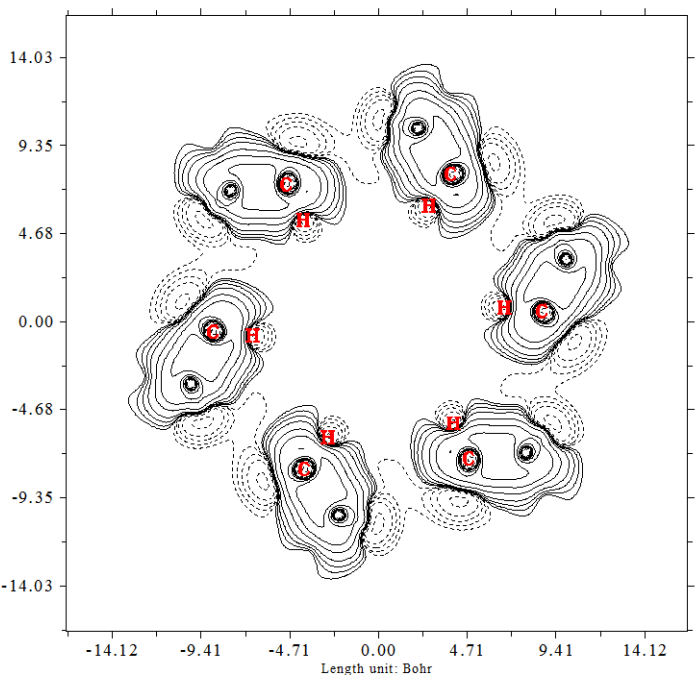

Scheme 3. Hamiltonian kinetics energy density G(r) of $\alpha$-Cyclodextrin.

Conclusion

At the ring centers of the shielding spaces of aromatic molecules, the absolute magnetic shielding computed at ring centers are applied as an aromaticity and antiaromaticity criterion by the NICS method.

We have concentrated on statistical calculation through Monte-Carlo for the asymmetry $(\eta)$ and skew $(\kappa)$ parameters. The expectation of these parameters such as $\left(\eta^{*}\right),\left(\kappa^{*}\right)$ exhibited maximum abundance in the areas of the shielding spaces. 
The isotropy analogous with modified parameters of asymmetry, span, anisotropy and skew is called Modified isotropy " $\sigma_{\text {iso }}^{*}$ " this isotropy is most considerable as an aromaticity criterion because it's miles arises from the maximum abundance of states, and it's stable value that is independent of the symmetric or nonsymmetric structures of the molecules. In contrast to the NICS, the S-NICS calculations would be lengthy without the use of any simplifying software.

The results revealed that positive S-NICS and NICS values for $\alpha$-Cyclodextrin indicate anti-aromaticity. It was observed from the values of $\left(\eta^{*}\right),\left(\kappa^{*}\right)$ based on our calculations for $\alpha$-Cyclodextrin is negatives.

\section{Acknowledgment}

The authors are content for collaboration of the IAU (science \& Research branch) for providing the software and computers.

\section{References}

Anet, F.A.L., O'Leary, D.J. (1992). The Shielding Tensor, Part II: Understanding its Strange Effects on Relaxation. Concepts Magn. Reson. http://doi.org/10.1002/cmr.1820040103.

Ardalan, T., Ardalan, P., Monajjemi, M. (2014). Nano Theoretical Study of a $\mathrm{C}_{16}$ Cluster as a Novel Material for Vitamin C Carrier. Fullerenes, Nanotubes and Carbon Nanostructures. http://doi.org/10.1080/1536383X.2012.717561.

Beenakker, J. J. M., Knaap, H. F. P., Sanctuary, B. C., (1973). in Transport Phenomena, AIP Conference Proceedings, edited by J. Kestin, (American Institute of Physics, New York). 1l, 21

Bhaskara-Amrit, U.R., Agrawa, P., Warmoeskerken, M. (2011). Application of $\beta$ Cyclodextrin in textiles. AUTEX Res J. http://doi.org/No4-2011/0020_ll.

Boonyarattanakalin, K., Wolschann, P., Toochinda, P., Lawtrakul, L.. (2012). Molecular dynamics simulations of UC781-cyclodextrins inclusion complexes in aqueous solution. Eur J Pharm Sci. http://doi.org/10.1016/j.ejps.2012.08.004. 
Del Valle, E.M.M. (2003). Cyclodextrins and their uses: a review. Prpcbio. http://doi.org/10.1016/S0032-9592(03)00258-9.

Feixas, F., Matito, E., Poater, J., Solà, M. (2008). On the performance of some aromaticity indices: a critical assessment using a test set. J. Comput. Chem. http://doi.org/10.1002/jcc.20914.

Fermeglia, M., Ferrone, M., Lodi, A., Pricl, S. (2003). Host-guest inclusion complexes between anticancer drugs and $\beta$-cyclodextrin: computational studies. Carbohyd Polym. http://doi.org/10.1016/S0144-8617(03)00011-0.

Fias, S., Van Damme, S., Bultinck, P. (2008). Multidimensionality of Delocalization Indices and Nucleus Independent Chemical Shifts in Polycyclic Aromatic Hydrocarbons. J. Comput. Chem. http://doi.org/10.1002/jcc.21520.

Frueh, D. (2002). Internal motions in proteins and interference effects in nuclear magnetic resonance. Prog. Nucl. Magn. Reson. Spectrosc. http://doi.org/10.1016/S00796565(02)00051-1.

Ghatee, M.H., Sedghamiz, T. (2014). Chiral recognition of Propranolol enantiomers by $\beta$-Cyclodextrin: Quantum chemical calculation and molecular dynamics simulation studies. J. Chem. Phys. http://doi.org/10.1016/j.chemphys.2014.10.008.

Hehre, W.J., Ditchfield, R., Radom, L., Pople, J.A. (1970). Molecular orbital theory of the electronic structure of organic compounds. V. Molecular theory of bond separation. J. Am. Chem. Soc. http://doi.org/10.1021/ja00719a006.

Herzfeld, J., Berger, A. E. (1980). Sideband intensities in NMR spectra of samples spinning at the magic angle. J. Chem. Phys. http://doi.org/10.1063/1.440136

Ibrahim, A.S.S., Al-Salamah, A.A., El-Toni, A.M., El-Tayeb, M.A., Elbadawi, Y.B. (2013) Immobilization of cyclodextrin glucanotransferase on aminopropyl-functionalized silica-coated superparamagnetic nanoparticles. Bio Electron J Bio. http://doi.org/10.2225/voll6-issue6-fulltext-8.

Ilkhani, A.R., Monajjemi, M. (2015). The pseudo Jahn-Teller effect of puckering in pentatomic unsaturated rings $\mathrm{C} 4 \mathrm{AE} 5, \mathrm{~A}=\mathrm{N}, \mathrm{P}, \mathrm{As}, \mathrm{E}=\mathrm{H}, \mathrm{F}, \mathrm{Cl}$. M. Computational and Theoretical Chemistry. http://doi.org/10.1016/j.molstruc.2015.05.029.

Jiao, H., Schleyer, P.V.R. (1995). Antiaromaticity: Evidence from magnetic criteria. J. Am. Chem. Soc. (1995). http://doi.org/10.1063/1.47865.

Katritzky, A.R., Barczynski, P., Musumarra, G., Pisano, D., Szafran, M. (1989) Aromaticity as a Quantitative Concept. 1. A Statistical Demonstration of the Orthogonality of "Classical" and "Magnetic" Aromaticity in Five- and Six-Membered Heterocycles. J. Am. Chem. Soc. http://doi.org/10.1021/ja00183a002. 
Kruszewski, J., Krygowski, T.M. (1972). Definition of aromaticity basing on the harmonic oscillator model. Tetrahedron Letters. http://doi.org/10.1016/S00404039(01)94175-9

Luginbhl, P., Wuthrich, K. (2002) Semi-classical nuclear spin relaxation theory revisited for use with biological macromolecules. Progress in Nuclear Magnetic Resonance Spectroscopy. http://doi.org/10.1016/s0079-6565(01)00043-7.

Mahdavian, L., Monajjemi, M. (2010). Alcohol sensors based on SWNT as chemical sensors: Monte Carlo and Langevin dynamics simulation. Microelectronics Journal. http://doi.org/10.1016/j.mejo.2010.01.011.

Martin, N.H., Nance, K. H. (2002). Modeling through-space magnetic shielding over ethynyl, cyano, and nitro groups. J. Mol. Graphics Modell. http://doi.org/10.1016/S10933263(02)00120-1.

Mason, J. (1993). Conventions for the reporting of nuclear magnetic shielding (or shift) tensors suggested by participants in the NATO ARW on NMR shielding constants. Solid State Nucl. Magn. Reson. http://doi.org/10.1016/0926-2040(93)90010-K.

Monajjemi, M. (2012). Quantum investigation of non-bonded interaction between the $\mathrm{B}_{15} \mathrm{~N}_{15}$ ring and $\mathrm{BH}_{2} \mathrm{NBH}_{2}$ (radical, cation, anion) systems: A nano molecularmotor. Struct. Chem. http://doi.org/10.1007/s11224-011-9895-8.

Monajjemi, M. (2013). None bonded interaction between BnNn (stator) and BN (-, 0, + ) B (rotor) systems: A quantum rotation in IR region. Chemical Physics. http://doi.org/10.1007/sll224-011-9895-8.

Monajjemi, M., Boggs, J.E. (2013). A new generation of $\mathrm{B}_{\mathrm{n}} \mathrm{N}_{\mathrm{n}}$ rings as a supplement to boron nitride tubes and cages. J. Phys. Chem. A. http://doi.org/10.1021/jp312073q.

Monajjemi, M., Chahkandi, B. (2005). Theoretical investigation of hydrogen bonding in Watson-Crick, Hoogestein and their reversed and other models: Comparison and analysis for configurations of adenine-thymine base pairs in 9 models. Journal of Molecular Structure: THEOCHEM. http://doi.org/10.1016/j.theochem.2004.09.048.

(2005).

Monajjemi, M., Falahati, M., Mollaamin, F. (2013). Computational investigation on alcohol nanosensors in combination with carbon nanotube: a Monte Carlo and ab initio simulation. Ionics. http://doi.org/10.1007/s11581-012-0708-x.

Monajjemi, M., Honarparvar, B., Nasseri, S.M., Khaleghian, M. (2009) NQR and NMR study of hydrogen bonding interactions in anhydrous and monohydrated guanine cluster model: a computational study. Journal of Structural Chemistry.. http://doi.org/10.1007/s10947-009-0009-z. 
Monajjemi, M., Karachi, N., Mollaamin, F. (2014). The investigation of sequencedependent interaction of messenger RNA binding to carbon nanotube. Fullerenes, Nanotubes and Carbon Nanostructures. http://doi.org/10.1080/1536383X.2012.717557.

Monajjemi, M., Ketabi, S., Amiri, A. (2006). Monte Carlo simulation study of melittin: Protein folding and temperature dependence. A. Russian Journal of Physical Chemistry. (2006). http://doi.org/10.1134/S0036024406130103.

Monajjemi, M., Khaleghian, M. (2011). EPR Study of Electronic Structure of [ $\left.\mathrm{CoF}_{6}\right]_{3-}$ and $\mathrm{B}_{18} \mathrm{~N}_{18}$ Nano Ring Field Effects on Octahedral Complex. J. Cluster Sci. http://doi.org/10.1007/s10876-011-0414-2.

Monajjemi, M., Lee, V.S., Khaleghian, M., Honarparvar, B., Mollaamin, F. (2010). Theoretical description of electromagnetic nonbonded interactions of radical, cationic, and anionic $\mathrm{NH}_{2} \mathrm{BHNBHNH}_{2}$ inside of the $\mathrm{B}_{18} \mathrm{~N}_{18}$ nanoring. J. Phys. Chem. C. http://doi.org/10.1021/jpl04274z.

Monajjemi, M., Mohammadian, N.T. (2015). S-NICS: An Aromaticity Criterion for Nano Molecules. J Comput Theo Nano. http://doi.org/10.1166/jctn.2015.4458.

Monajjemi, M., Rajaeian, E., Mollaamin, F., Naderi, F., Saki, S. (2008 a). Investigation of NMR shielding tensors in 1, 3 dipolar cycloadditions: solvents dielectric effect. Physics and Chemistry of Liquids. http://doi.org/10.1080/00319100601124369.

Monajjemi, M., Razavian, M.H., Mollaamin, F., Naderi, F., Honarparvar, B. (2008 b). A theoretical thermochemical study of solute-solvent dielectric effects in the displacement of codon-anticodon base pairs. Russian Journal of Physical Chemistry A. (2008). http://doi.org/10.1134/S0036024408130207.

Pan, W., Zhang, D., Zhan, J.: (2011) Theoretical investigation on the inclusion of TCDD with $\beta$-cyclodextrin by performing QM calculations and MD simulations. J Hazard Mater. http://doi.org/10.1016/j.jhazmat.2011.07.010.

Ramírez, M.; Migliore, B.; Guío, J.; (2011). Avances en la síntesis de los sistemas 1-,2-y 3-benzazepinas y su aplicación en el diseño de nuevos compuestos con actividad farmacológica en el Sistema Nervioso Central, Revista de la Universidad del Zulia, 2 (3), 7 33

Samiei Soofiand, N., Monajjemi, M.: (2016) A study of $\mathrm{Fe}_{3} \mathrm{O}_{4} @ \mathrm{Si}_{18} \mathrm{O}_{27}$ catalyst through Statistical-Nucleus Independent Chemical Shifts (S-NICS) method. Orien J Chem. (2016). http://doi.org/10.13005/ojc/320504

Schleyer, P.V.R., Jiao, H., van Eikema Hommes, N.J.R., Malkin, V.G., Malkina, O.L.: (1997). An Evaluation of the Aromaticity of Inorganic Rings: Refined Evidence from Magnetic Properties. J. Am. Chem. Soc. http://doi.org/10.1021/ja9719135. 
REVISTA DE LA UNIVERSIDAD DEL ZULIA. 3ª época. Año $11 N^{\circ}$ 29, 2020

Hediyeh Sadat Ghazimokri et al./// Drug delivery via $\alpha$-Cyclodextrin ...

Schleyer, P.V.R., Maerker, C., Dransfeld, A., Jiao, H., van Eikema Hommes, N.J.R. (1996) Nucleus-Independent Chemical Shifts: A Simple and Efficient Aromaticity. Probe. J. Am. Chem. Soc. http://doi.org/10.1021/ja960582d.

Stepien, B.T., Krygowski, T.M., Cyranski, M.K., Mlochowski, J., Orioli, P., Abbate, F. (2004). How far is the $\pi$-electron delocalization of the phenanthrene moiety modified in the aza-analogues and their N-oxides. ARKIVOC. (2004). http://doi.org/10.3998/ark.5550190.0005.316.

Yahyaei, H., Monajjemi, M.: (2014) Theoretical study of different solvent and temperature effects on double-walled carbon nanotubes (DWNTs) and calixarene with amino acid: A QM/MM study. Fullerenes, Nanotubes and Carbon Nanostructures. http://doi.org/10.1080/1536383X.2012.684190. 